\title{
Solubility and aging of lead magnesium niobate in water
}

\author{
Aylin Şakar-Deliormanlı ${ }^{a}{ }^{*}$, Erdal Çelik ${ }^{b}$, Mehmet Polat $^{a}$ \\ ${ }^{a}$ Izmir Institute of Technology, Chemical Engineering Department, Urla, Izmir, Turkey \\ ${ }^{\mathrm{b}}$ Dokuz Eylul University, Metallurgy and Materials Engineering Department, Izmir, Turkey \\ Received 4 September 2007; received in revised form 23 October 2007; accepted 4 January 2008 \\ Available online 8 April 2008
}

\begin{abstract}
Lead magnesium niobate (PMN) is an important relaxor ferroelectric material commonly employed in multilayer capacitor and actuator manufacturing owing to its high dielectric constant and superior electrostrictive properties. However, stability of this material in water is not very well known and there is need for a detailed investigation. In this research, solubility of lead magnesium niobate powders in water was determined as a function of solids concentration. The obtained results showed that the amount of cation leaching from the PMN surface depends on the pH value of the suspension and the solids concentration. The $\mathrm{Pb}^{2+}$ and $\mathrm{Mg}^{2+}$ ion dissolution was very high especially in the acidic $\mathrm{pH}$ range. Nevertheless, neither the dissolution mechanism nor the effects of dissolved ions on the stability were the same for those ions. The study provides new aspects on the solubility of perovskite materials which possess more than one soluble cation in their structure.
\end{abstract}

(C) 2008 Elsevier Ltd and Techna Group S.r.l. All rights reserved.

Keywords: A. Suspensions; B. Surfaces; D. Perovskites; Ceramics; Relaxor ferroelectrics

\section{Introduction}

Lead magnesium niobate (PMN) is a relaxor ferroelectric material which is characterized by a diffuse phase transition over a broad temperature range and a frequency dependent maximum in its relative dielectric permittivity $[1,2]$. It has many potential applications such as actuators, motors, pumps, optical scanning systems, and vibration isolators [3,4]. The most common application of PMN is in multilayer ceramic capacitors (MLCC).

The manufacturing of electronic devices such as MLCC composed of perovskite materials generally involves a colloidal process which requires preparation of colloidal suspensions. The previous studies on this subject include the preparation of lead magnesium niobate-lead titanate (PMN-PT) suspensions in solvents other than water [5-7]. PMN-PT powders can be dispersed in organic solvents, to get well-dispersed suspensions. However, the use of aqueous media instead of organic solvents is desirable nowadays due to economic and environmental considerations [8]. Therefore, understanding the PMN$\mathrm{H}_{2} \mathrm{O}$ system is essential in producing high quality PMN

\footnotetext{
* Corresponding author. Tel.: +90 232 7506697; fax: +90 2327506645. E-mail address: aylindeliormanli@iyte.edu.tr (A. Şakar-Deliormanlı).
}

ceramics. On the other hand, the behavior of PMN particles in water medium has not been widely reported.

Most perovskites are not thermodynamically stable in water. Metal ions in the ceramic powders are dissolved in water, which affects the dispersion stability of the suspension [8,9]. Perovskite materials such as PMN have the general chemical formula, $\mathrm{ABO}_{3}(\mathrm{~A}=\mathrm{Na}, \mathrm{Ca}, \mathrm{Ba}, \mathrm{Pb}, \mathrm{Mg}$, etc. $)$ and $(\mathrm{B}=\mathrm{Ti}, \mathrm{Nb}$, $\mathrm{Zr}$, etc.) [10]. In perovkites the cation at the A site is generally soluble in water whereas the B site cation that is only slightly soluble overall the practical $\mathrm{pH}$ range. Therefore, A site cation undergoes incongruent dissolution leaving an interface which is relatively rich in the B site cation [11].

In this study solubility characteristics of the cations that constitute PMN was examined as a function of suspension $\mathrm{pH}$ and solids concentration. Effect of cation leaching on the surface bond formation and the microstructure of the PMN powders was also investigated.

\section{Experimental}

Lead magnesium niobate, $\mathrm{Pb}\left(\mathrm{Mg}_{1 / 3} \mathrm{Nb}_{2 / 3}\right) \mathrm{O}_{3}$ powder which was produced by combustion spray pyrolysis method provided by Praxair Specialty Ceramics (Woodinville WA). Powder purity is $99.9 \%$ as reported by the manufacturer. Bulk density 
(Helium pycnometer Micromeritics 1330), and the BET surface area (Micromeritics ASAP 2400, Norcross, GA) of the powder are measured to be $7.967 \mathrm{~g} / \mathrm{cm}^{3}$ and $1.168 \mathrm{~m}^{2} / \mathrm{g}$, respectively. Particle size distribution of the powder was obtained using a particle size analyzer (Model CAPA-700, Horiba, Ltd., Tokyo, Japan) and the $\mathrm{d}_{50}$ of the powder was measured to be $2.03 \mu \mathrm{m}$. Crystal structure of the PMN powder was identified using X-ray diffractometer (Philips, XL30-S FEG). Morphology was investigated using Scanning Electron Microscope (Philips X'Pert Pro). Fig. 1 shows the microstructure and the crystal phase of the PMN powder used in the study.

Aqueous PMN suspensions were prepared at different solids loadings ranging from 0.1 to $10 \mathrm{vol} \%$ using deionized water. Suspensions were magnetically stirred for $24 \mathrm{~h}$ prior to the measurements at room temperature. Adjustments of the $\mathrm{pH}$ were performed using $1 \mathrm{M}$ solutions of $\mathrm{HNO}_{3}$ and $\mathrm{NH}_{3} \mathrm{OH}$. The $\mathrm{pH}$ values of the suspensions were controlled during the stirring period and further adjustments were performed when necessary.

Solubility of $\mathrm{Pb}^{2+}, \mathrm{Mg}^{2+}$ and $\mathrm{Nb}^{5+}$ ions in the PMN structure was examined using Inductively Coupled Plasma Mass Spectroscopy (ICP-MS Agilent, 7500 Series) and Inductively Coupled Plasma Atomic Emission Spectroscopy (ICP-AES Optima 2000 DV PerkinElmer Norwalk, CT, USA). For this purpose suspensions prepared at different solids loadings according to the procedure described in the previous section were centrifuged at $4000 \mathrm{rpm}$ for $1 \mathrm{~h}$ to obtain a clear supernatant. The supernatants were further filtered from $0.02 \mu \mathrm{m}$ microfilters to eliminate any possible particles in solution. The amounts of $\mathrm{Pb}^{2+}, \mathrm{Mg}^{2+}$ and $\mathrm{Nb}^{5+}$ in particle-free supernatants were determined using ICP-AES (for $5 \mathrm{vol} \%$ suspensions) and ICP-MS (for other solid concentrations).

Mobility of PMN suspensions were directly determined by electrokinetic sonic amplitude measurements using an electroacoustic analyzer (ESA-9800, Matec Applied Sciences, Nortborough, MA). To ensure dispersion, the suspensions were ultrasonicated for $2.5 \mathrm{~min}$ using an ultrasonic horn (550 Sonic Dismembrator, Fisher Scientific, Pardubice, Czech Republic)

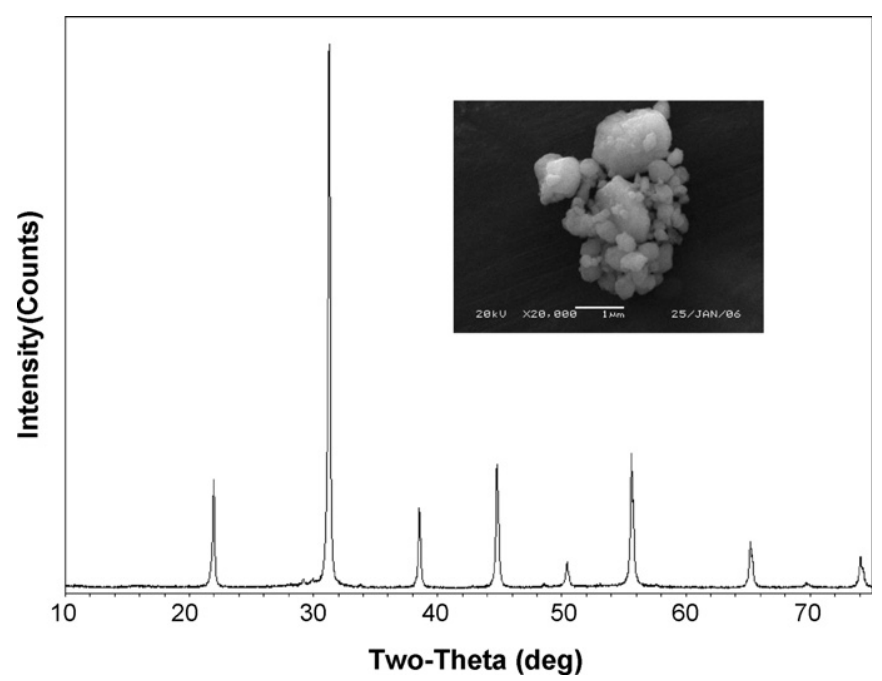

Fig. 1. X-ray diffraction pattern and the SEM micrograph of the as-received PMN powder. prior to measurements. The ESA measurements were checked against a 10 vol\% Ludox suspension having a zeta potential of $-38 \mathrm{mV}$. Experiments were performed triplicate, and the results given are the average of 10 measurements.

Structural bonds of the PMN powders after aging in water at different conditions were analyzed using Fourier Transform Infrared Spectroscopy (FTIR-8201, Shimadzu, Japan). Microstructure and crystal structure of the PMN powders aged in water at different conditions prior to a heat treatment at $1100{ }^{\circ} \mathrm{C}$ for $2 \mathrm{~h}$ (heating rate, $5{ }^{\circ} \mathrm{C} / \mathrm{min}$ ) was examined using a scanning electron microscope (Philips, XL30-S FEG) and X-ray diffractometer (Philips, X'Pert Pro), respectively.

\section{Results and discussion}

In the first part of the study cation dissolution from the PMN surface was examined as a function of solution $\mathrm{pH}$. The amount of cation concentration in solution obtained from a suspension having a solids concentration of 5 vol\% was investigated in our previous study [14]. Accordingly, Fig. 2 shows that the lead and magnesium ion concentrations increase with decreasing $\mathrm{pH}$. Especially the $\mathrm{Pb}^{2+}$ concentration increases dramatically in the acidic region. Though the $\mathrm{Mg}^{2+}$ dissolution was also $\mathrm{pH}$ dependent the dissolution rate was almost an order of magnitude smaller compared to that observed with $\mathrm{Pb}^{2+}$ at low $\mathrm{pH}$ values. But it was observed that $\mathrm{Mg}^{2+}$ dissolution is more significant at neutral $\mathrm{pH}$ values. On the other hand, $\mathrm{Nb}^{5+}$ exhibited rather low dissolution under the same conditions. The $\mathrm{Nb}^{5+}$ concentrations in the acidic region were below the detection limit of the analyzing device [14].

Previously Neubrand et al. [12] investigated the dissolution of $\mathrm{Ba}^{2+}$ ions from the barium titanate in water. They found that the amount of barium leached increases as the $\mathrm{pH}$ decreases. In fact the increase in the dissolved metal ion concentration with decreasing $\mathrm{pH}$ considered to be a general behavior for most perovkites in water [13]. However, in $\mathrm{Pb}-\mathrm{Mg}-\mathrm{Nb}-\mathrm{H}_{2} \mathrm{O}$ system A-site cations, $\mathrm{Pb}^{2+}$ and $\mathrm{Mg}^{2+}$, are soluble that makes the surface chemistry more complex compared to other perovskites such as $\mathrm{BaTiO}_{3}$ and PZT.

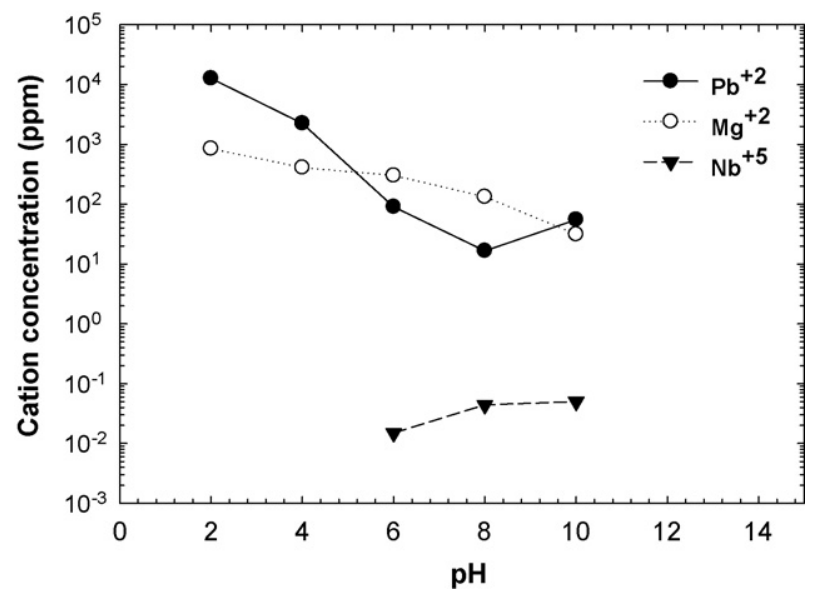

Fig. 2. Dissolved $\mathrm{Pb}^{2+}, \mathrm{Mg}^{2+}$ and $\mathrm{Nb}^{2+}$ ion concentration as a function of suspension $\mathrm{pH}$ (solids concentration $5 \mathrm{vol} \%$ ) [14]. 


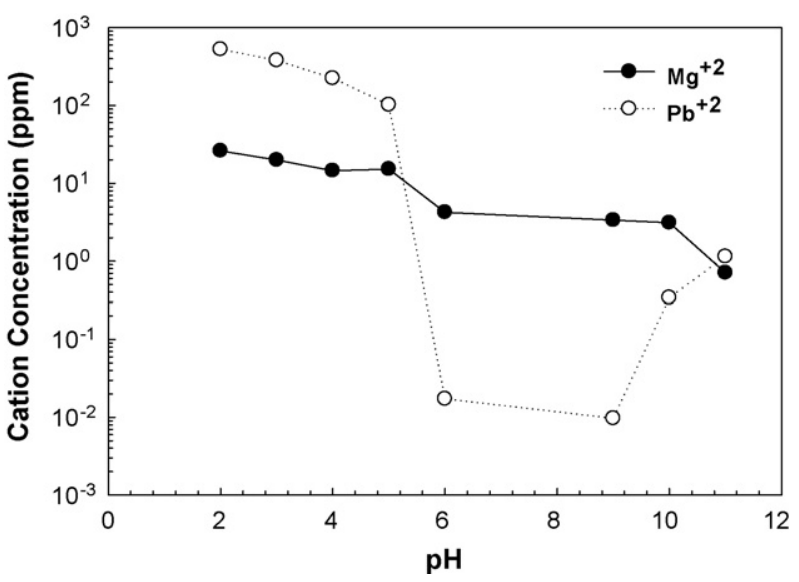

Fig. 3. Dissolved $\mathrm{Pb}^{2+}$, and $\mathrm{Mg}^{2+}$ ion concentration as a function of suspension $\mathrm{pH}$ (solids concentration $0.1 \mathrm{vol} \%$ ).

Adair et al. [11] reported the dissolution types dictated by the ceramic materials and solution $\mathrm{pH}$. According to their work, the most multi-component metal oxides such as barium titanate generally follow incongruent type dissolution and the dissolution mechanism strongly depends on the $\mathrm{pH}$ value.

In the current study, cation dissolution from PMN surface was investigated at some other solid concentrations namely 0.1 , 1 and $10 \mathrm{vol} \%$. The results are given in Figs. 3-5. According to Figs. 3 and $4, \mathrm{~Pb}^{2+}$ ion concentration increases dramatically starting from $\mathrm{pH} 6$ for low solids loading suspensions. However, the increase in cation concentration for higher solids loading suspensions was rather low. The dissolution percentage of $\mathrm{Pb}^{2+}$ and $\mathrm{Mg}^{2+}$ as a function of solids concentrations is drawn in Fig. 5, showing that cation dissolution from PMN surface increases as the solids concentration decreases.

The increase of cation dissolution at low solids loading suspensions can be explained based on the transport process of particles in the liquid phase. When the PMN is suspended in water a surface layer is developed due to the deficiency of the dissolving $\mathrm{Pb}^{2+}$ and $\mathrm{Mg}^{2+}$ ions. Specifically, the surface layer forms because of the mass transport limited dissolution. Without the mass transport limitation the entire particle would

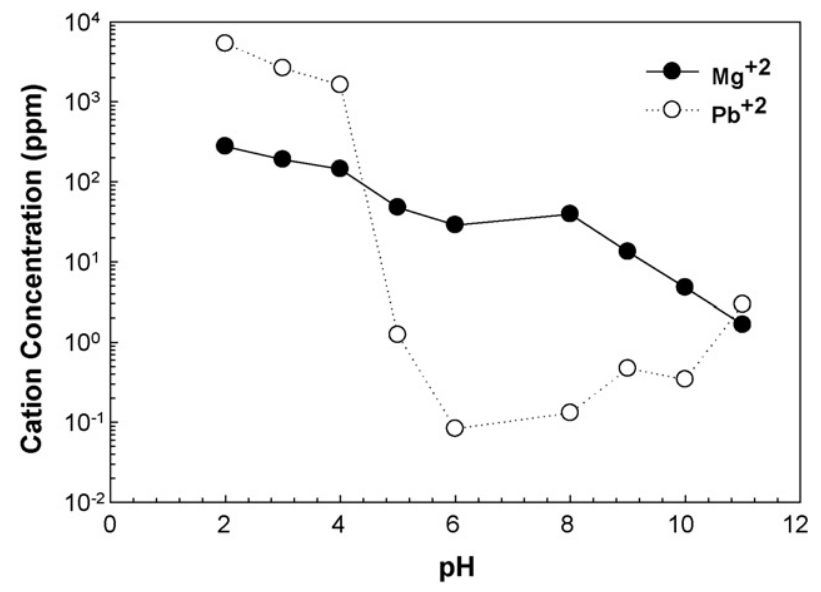

Fig. 4. Dissolved $\mathrm{Pb}^{2+}$, and $\mathrm{Mg}^{2+}$ ion concentration as a function of suspension $\mathrm{pH}$ (solids concentration $1 \mathrm{vol} \%$ ).

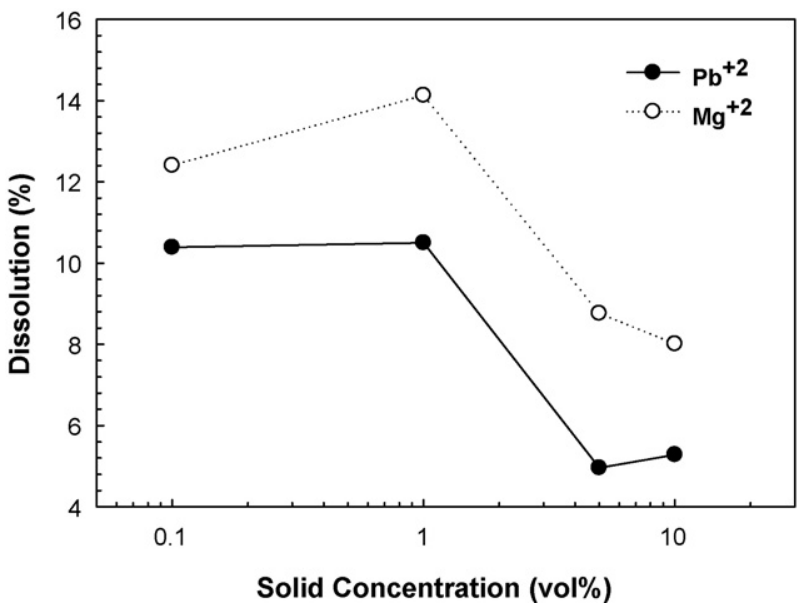

Fig. 5. Cation dissolution (in percent) from PMN surface as a function of solids concentration, at $\mathrm{pH} 2$.

be converted to the niobium oxide at low solids concentration and in acidic $\mathrm{pH}$ conditions. This means that, the surface layer on PMN particles in acidic region will be thicker in dilute suspensions compared to the concentrated suspensions. As much as the rate of surface layer growth in concentrated suspensions is inhibited by the mass transfer, the dissolution rate will be lower in concentrated PMN suspensions [14].

Previously Paik and Hackley [15] investigated the dissolution of barium titanate in water as a function of solids concentration. Accordingly, in barium titanate/water system, $\mathrm{Ba}^{2+}$ ions dissolve from the surface, as a function of solids concentration. Therefore, it is possible to say that the results of the current study are in good agreement with the previous study of Paik and co-workers. Fig. 6 displays the kinetics of the $\mathrm{Pb}^{2+}$ and $\mathrm{Mg}^{2+}$ dissolution at $\mathrm{pH}$ values 6 and 9. Depending on this, the dissolution rate of both cations was nearly constant at $\mathrm{pH} 9$ within the time period studied. Nonetheless, dissolution rates were quite different at $\mathrm{pH} 6$. At this $\mathrm{pH}$ the lead concentration reaches considerably high levels immediately after the initial contact of powder with water and decreases gradually with time as seen from Fig. 6. The decrease in the $\mathrm{Pb}^{2+}$ ion concentration in solution phase may be attributed to the re-adsorption of the

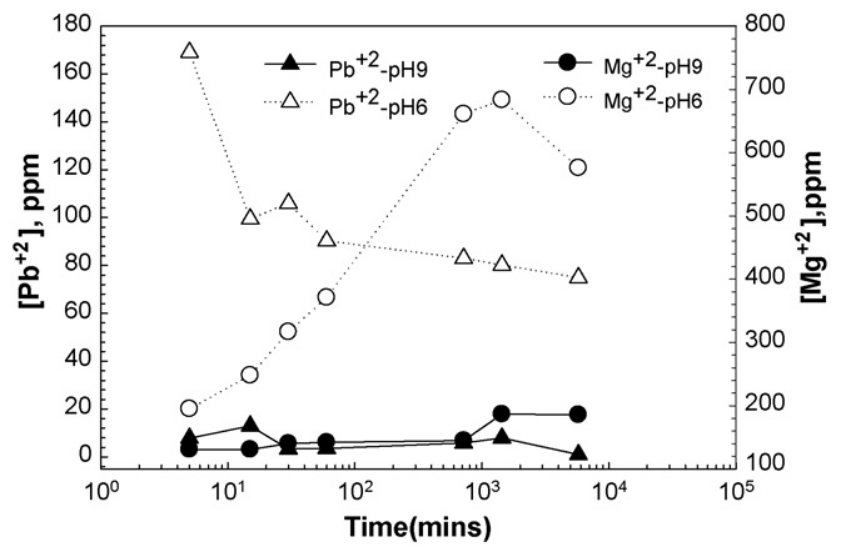

Fig. 6. Dissolved $\mathrm{Pb}^{2+}$, and $\mathrm{Mg}^{2+}$ concentrations as a function of stirring time in water at $\mathrm{pH} 6$ and 9 . 


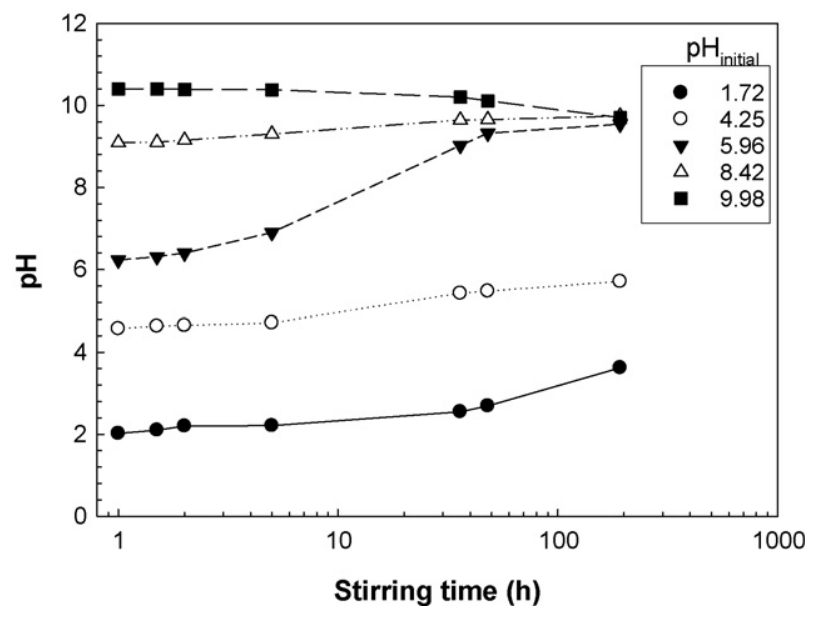

Fig. 7. The $\mathrm{pH}$ change of 1 vol\% PMN suspensions as a function of stirring time in water and initial $\mathrm{pH}$ treatment.

free $\mathrm{Pb}^{2+}$ ions onto the hydrated PMN surface. As it is described above, dissolution of $\mathrm{Pb}^{2+}$ and $\mathrm{Mg}^{2+}$ ions were high at this $\mathrm{pH}$ value compared to the dissolution rate at $\mathrm{pH}$ 9. On the other hand, $\mathrm{Mg}^{2+}$ ion concentration showed gradual increase with time at $\mathrm{pH} 6$ and reached a maximum value after $24 \mathrm{~h}$, indicating a decrease for longer contact times. According to this picture it is possible to conclude that $\mathrm{Mg}^{2+}$ and $\mathrm{Pb}^{2+}$ ions demonstrate different behavior after they dissolve from the PMN surface. $\mathrm{Mg}^{2+}$ and $\mathrm{Pb}^{2+}$ ions possibly form complexes with the $-\mathrm{OH}$ ions in water. The increase in the $\mathrm{pH}$ of the PMN suspensions from $\mathrm{pH} 6$ to 8.6 may support this argument (see Fig. 7). This increase in $\mathrm{pH}$ may be attributed to the complex formation between the cations (notably $\mathrm{Pb}^{2+}$ ) dissolved from PMN surface and the $-\mathrm{OH}$ ions in water [16]. Figs. 8 and 9 denote the formation $\mathrm{pH}$ of various lead and magnesium hydroxides. According to these figures, formation of $\mathrm{PbOH}$ or $\mathrm{Pb}_{4}(\mathrm{OH})_{4}{ }^{4+}$ may be responsible for the rapid increase in $\mathrm{pH}$ of the PMN suspension $\left(\mathrm{pH}_{\text {initial }} 6\right)$. Fig. 7 also depicts that the suspensions most probably consume the protons from solution. This may be attributed to the adsorption of protons from solution onto the PMN surface which should yield a positive surface charge at these low $\mathrm{pH}$ values. Such increase in the $\mathrm{pH}$

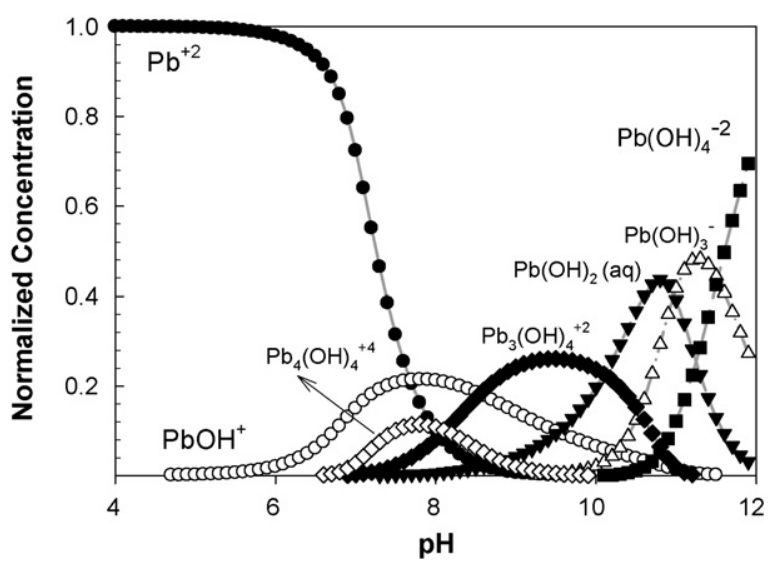

Fig. 8. Normalized concentration of various lead compounds as a function of suspension $\mathrm{pH}$, obtained by Visual MINTEQ ver. 2.12.

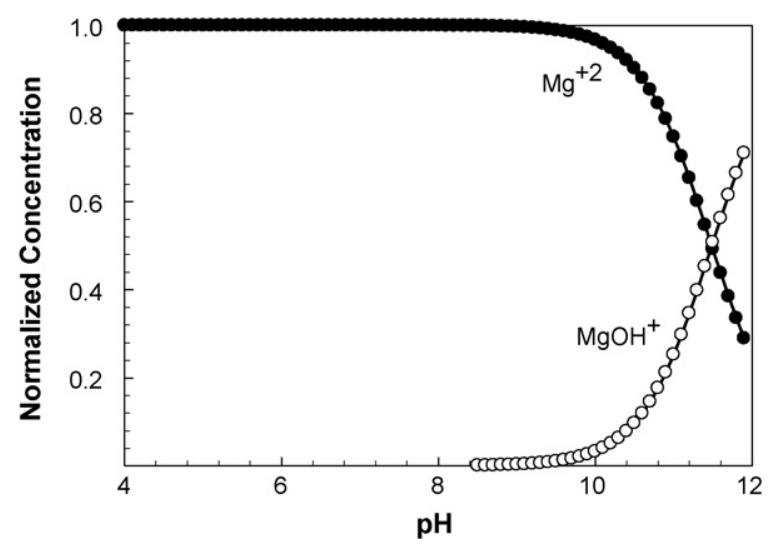

Fig. 9. Normalized concentration of magnesium hydroxide as a function of suspension $\mathrm{pH}$, obtained by Visual MINTEQ ver. 2.12 .

due to consumption of protons must be associated by the cation dissolution from the PMN surface at the acidic $\mathrm{pH}$ range. Such effect would be more pronounced with increasing solids content.

In the study mobility measurements were performed to investigate the change in dynamic mobility of PMN suspensions with time. Fig. 10 demonstrates the mobility curves for the suspension prepared at $0.1 \mathrm{vol} \%$ at $\mathrm{pH} 8$ and 2 . Measurements were repeated under the same conditions at $5 \mathrm{vol} \%$ to understand the effect of solids concentration on the dynamic mobility. It is clear from Fig. 10, the mobility of the particles increases with time in the case of the dilute suspension $(0.1 \mathrm{vol} \%)$ at $\mathrm{pH} 2$. On the other hand, the mobility of the particles in the case of $5 \mathrm{vol} \%$ is nearly constant through the measurement period. This behavior can be attributed to the higher dissolution rate of lead and magnesium ions in dilute suspension compared to the more concentrated one.

Previously Paik et al. reported that for barium titanate system, the dissolution process can be divided into three stages. First, incongruent dissolution in the first few minutes after initial contact with the acidic solution followed by a mass transport limited second step [15,17]. A similar dissolution process is valid for the $\mathrm{PMN}$-water system. In the first step $\mathrm{Pb}^{2+}$

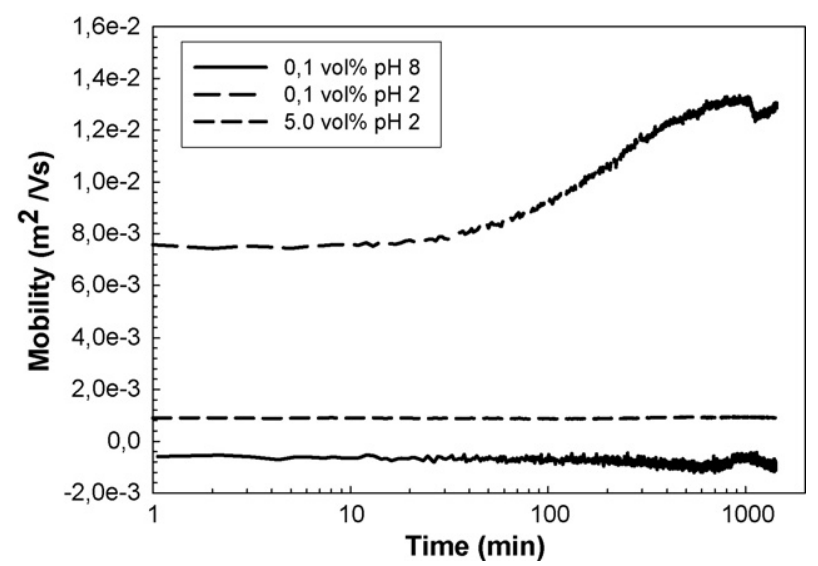

Fig. 10. Dynamic mobility of PMN suspensions prepared at different conditions as a function of stirring time. 


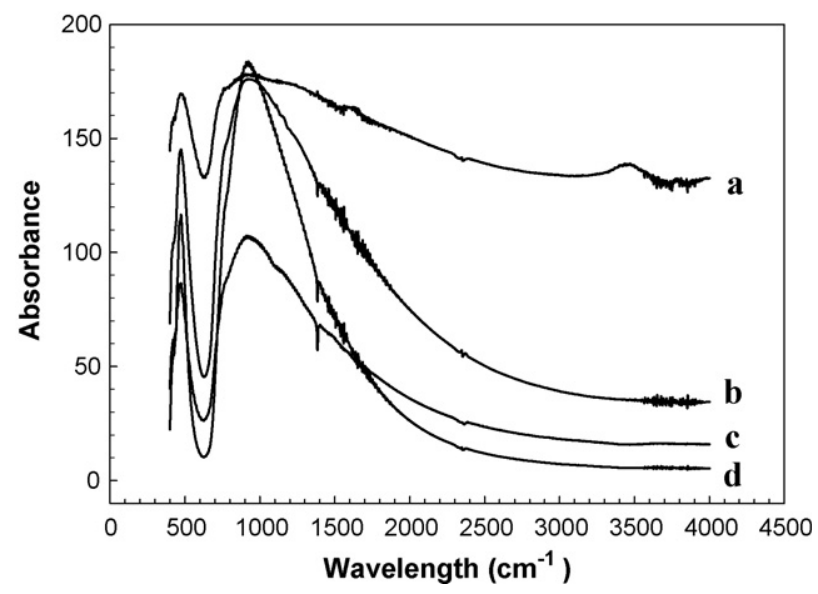

Fig. 11. FTIR spectra of PMN powders aged in water (a) no water treatment, (b) $24 \mathrm{~h}, \mathrm{pH} 6$, (c) 4 days $\mathrm{pH} 9$ and (d) 24 h, pH 9.

and $\mathrm{Mg}^{2+}$ must diffuse out through a growing reactive surface layer. In the final stage, dissolution slows considerably and following possibilities may arise: a steady-state equilibrium concentration is reached, a thick depletion layer may form and leads to passivation; or the particles are completely converted to Nb-rich phase.

The FTIR spectra of the PMN powders aged in water at different conditions is shown in Fig. 11. Results suggest that the vibrational band over the range of $3200-3700 \mathrm{~cm}^{-1}$ indicates the $-\mathrm{OH}$ groups in the sample. The band over the range of 500-900 $\mathrm{cm}^{-1}$ corresponds to the metal oxygen bonds [18]. Wang et al. [8] analyzed the DRIFT spectra of the $\mathrm{BaTiO}_{3}$ and PZT powders after aging in water for several days. They observed surface carbonate formation which is shown at 1450 and $1400 \mathrm{~cm}^{-1}$ for barium titanate and lead zirconate titanate, respectively. Surface carbonate formation is an important problem faced during the aging of perovskites in water. It is well known that the presence of $\mathrm{CO}_{2}$ naturally dissolved in the water contributes to $\mathrm{BaTiO}_{3}$, instability and a tendency to form barium carbonate [19]. Nevertheless, in the current study surface carbonate formation was not observed for PMN powders.

It is a fact that local chemical inhomogeneties play an important role in abnormal grain growth in the perovskite structures exposed to the aqueous environment. Because broad distribution of the grain sizes may affect the desirable electric properties [11]. In our study it was shown that there is considerable amount of $\mathrm{Pb}^{2+}$ and $\mathrm{Mg}^{2+}$ ion dissolution from the PMN surface. Especially under very acidic conditions formation of niobium oxide-rich matrix was considered. Thus, there is a possibility for formation of A-site deficient structures if stoichiometric ratios were disturbed by ion dissolution. In order to investigate possible effects of ions dissolution from the oxide surface, PMN suspensions were stirred in water at room temperature at $\mathrm{pH} 9$ and 6 and a subsequent heat treatment was applied.

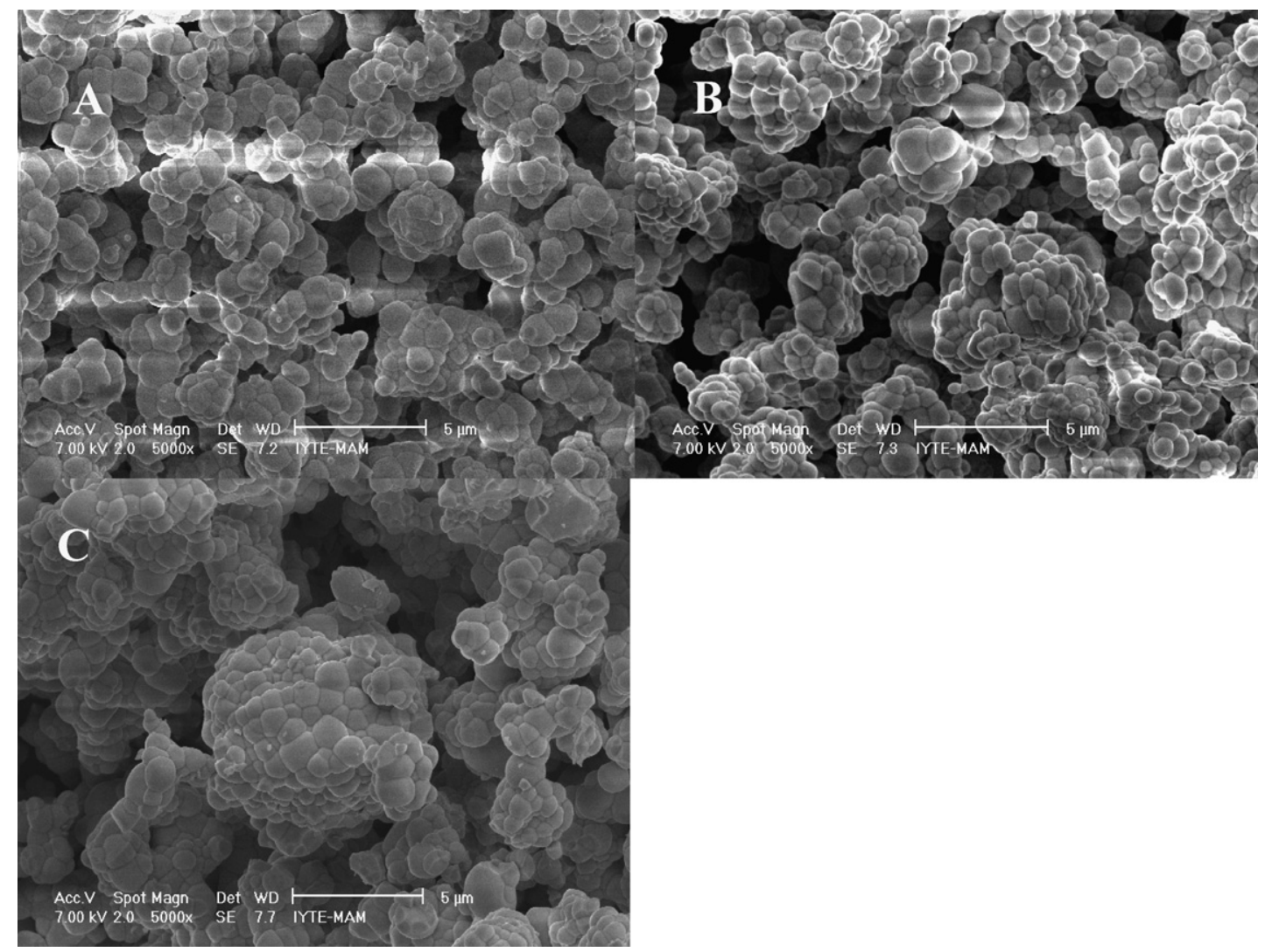

Fig. 12. SEM micrographs of PMN powders aged in water followed by calcination at $1100{ }^{\circ} \mathrm{C}$ for $2 \mathrm{~h}$ (A) No water treatment, (B) 4 days mixing in water, pH 9 and (C) $24 \mathrm{~h}$ mixing in water $\mathrm{pH} 6$. 


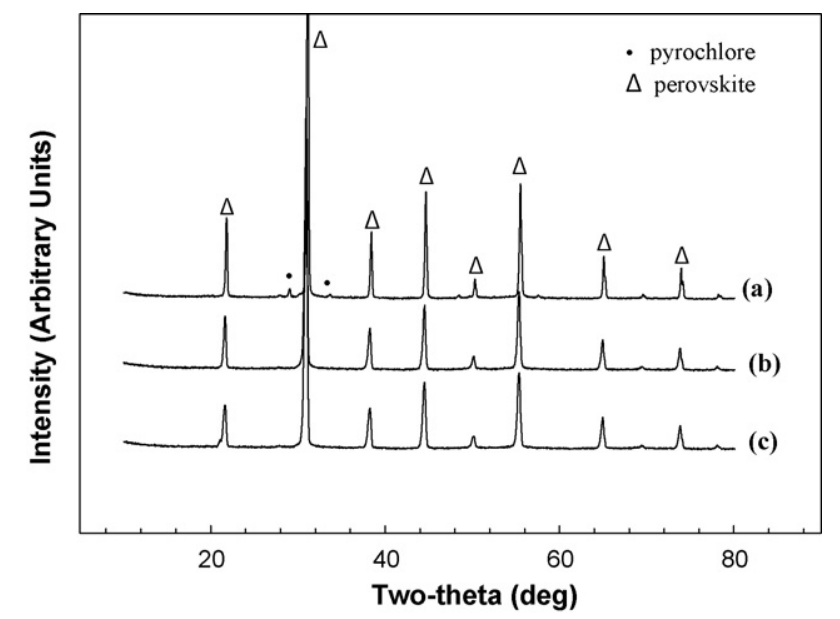

Fig. 13. XRD pattern of PMN powders aged in water followed by calcination at $1100{ }^{\circ} \mathrm{C}$ for $2 \mathrm{~h}$ (a) $24 \mathrm{~h}$ mixing in water $\mathrm{pH} \mathrm{6}$, (b) no water treatment and (c) 4 days mixing in water, $\mathrm{pH} 9$.

Fig. 12 denotes the SEM micrograph of the PMN powders mixed in water at different conditions followed by calcination at $1100{ }^{\circ} \mathrm{C}$ for $2 \mathrm{~h}$ (heating rate, $5^{\circ} \mathrm{C} / \mathrm{min}$ ).

According to Fig. 12B due to low ion dissolution from oxide surface at $\mathrm{pH} 9$ even very long contact times with water did not cause any detrimental effect in the microstructure of PMN. However calcination of the powders stirred in water at $\mathrm{pH} 6$ for shorter period $(24 \mathrm{~h})$ caused a partial increase in the grain size (Fig. 12C).

Similarly, according to Fig. 13a, small amount of pyrochlore formation was observed in the sample aged in water at $\mathrm{pH}$ 6. On the other hand, X-ray diffraction spectra of the sample prepared at $\mathrm{pH} 9$ showed that its crystal structure was pure perovskite and there is no formation of a second phase.

\section{Conclusions}

Chemical stability of lead magnesium niobate powders in water was investigated in this study. Solubility experiments showed that $\mathrm{Pb}^{2+}$ and $\mathrm{Mg}^{2+}$ ions dissolve from the PMN surface as a function of $\mathrm{pH}$ and solids concentration. Dissolution of $\mathrm{Pb}^{2+}$ and $\mathrm{Mg}^{2+}$ increased with decreasing $\mathrm{pH}$ value. Nevertheless, $\mathrm{Nb}^{5+}$ dissolution was negligible under the same conditions. It was concluded that $\mathrm{Pb}-\mathrm{Mg}-\mathrm{Nb}-\mathrm{H}_{2} \mathrm{O}$ system undergoes incongruent dissolution with selective leaching and protective passive film forms on the solid surface.

FTIR spectra of the PMN powders aged in water at different conditions revealed that there is no surface carbonate formation. Microstructural characterization demonstrates ion dissolution from PMN surface at specified conditions did not cause any detrimental effect on the properties of the sintered product.

\section{Acknowledgements}

ICP-AES and ESA measurements were performed at University of Illinois at Urbana Champaign, USA. Invaluable advice and support of Prof. Dr. Jennifer A. Lewis is gratefully acknowledged. The financial support and grant by The Scientific and Technological Research Council of Turkey (Tubitak NATO-A2) and T.R. Prime Ministry State Planning Organization (DPT) are acknowledged.

\section{References}

[1] S. Fengbing, L. Qiang, Z. Haisheng, L. Chunhong, Z. Shix, S. Dezhong, Phase formation and transitions in the lead magnesium niobate-lead titanate system, Mater. Chem. Phys. 83 (2004) 135-139.

[2] S.L. Swartz, T.R. Shrout, W.A. Schulze, L.E. Cross, Dielectric properties of lead magnesium niobate ceramics, J. Am. Ceram. Soc. 67 (1984) 311 315.

[3] H.S. Tzou, H.J. Lee, S.M. Arnold, Smart materials, precision sensors/ actuators, smart structures, and structronic systems, Mech. Adv. Mater. Struct. 11 (2004) 367-393.

[4] C. Pithan, D. Hennings, R. Waser, Progress in the synthesis of nanocrystalline $\mathrm{BaTiO}_{3}$ powders for MLCC, Int. J. Appl. Ceram. Technol. 2 (2005) $1-14$.

[5] H. Windlass, P. Markondeya Raj, D. Balamaran, Colloidal processing of polymer ceramic nanocomposites for integral capacitors, in: International Symposium on Advanced Packaging Materials Proceedings, 2001, pp. 393-398.

[6] S. Satoshi, E. Bidstrup-Allen, P. Kohl, Development of high-K photo definable epoxy composites for embedded capacitors, in: IEEE/CPMT International Electronics Manufacturing Technology Symposium Proceedings, 1998.

[7] A. Vishal, P. Chahal, R.R. Tummala, M.G. Allen, Improvements and recent advances in nanocomposite capacitors using a colloidal techniques, in: IEEE Electronic Components and Technology Conference Proceedings, 1998, pp. 165-170.

[8] Y.X. Wang, S. Lu, B.I. Lee, L. Mann, Dispersion and aging behavior of $\mathrm{BaTiO}_{3}$ and PZT in water, Mater. Res. Bull. 35 (2000) 25552563.

[9] W.H. Nesbitt, M.G. Bancroft, S.W. Fyfe, H.S. Karkhanis, A. Nishijima, S. Shigemitsu, Thermodynamic stability and kinetics of perovskite dissolution, Nature 289 (1981).

[10] S.L. Swartz, Topics in electronic ceramics, IEEE Transactions on Electrical Insulation 25 (1990) 935-987.

[11] J.H. Adair, J. Crampo, M.M. Mandanas, E. Suvaci, The role of material chemistry in processing $\mathrm{BaTiO}_{3}$ in aqueous suspensions, J. Am. Ceram. Soc. 89 (2006) 1853-1860.

[12] A. Neubrand, R. Lindner, P. Hoffmann, Room temperature solubility behavior barium titanate in aqueous media, J. Am. Ceram. Soc. 83 (2000) $860-864$.

[13] U. Paik, J.-G. Yeo, M.-H. Lee, V.A. Hackley, Y.-G. Jung, Dissolution and precipitation of barium at the particulate $\mathrm{BaTiO}_{3}$-aqueous solution interface, Mater. Res. Bull. 37 (2002) 1623-1631.

[14] A.M. Deliormanlı, E. Çelik, M. Polat, The isoelectric point of lead magnesium niobate, J. Am. Ceram. Soc. 90 (2007) 3314-3317.

[15] U. Paik, V.A. Hackley, Influence of solids concentration on the isoelectric point of aqueous barium titanate, J. Am. Ceram. Soc. 83 (2000) 23812384.

[16] W. Stumm, Chemistry of the Solid-Water Interface, Processes at the Mineral-Water and Particle-Water Interface in Natural Systems, John Wiley and Sons Inc., USA, 1992.

[17] U. Paik, S. Lee, A.V. Hackley, Influence of barium dissolution on the electrokinetic properties of colloidal $\mathrm{BaTiO}_{3}$ in an aqueous medium, $\mathrm{J}$ Am. Ceram. Soc. 86 (2003) 1662-1668.

[18] W. Beng Ng, J. Wang, S. Choon Ng, L.M. Gan, Processing and characterization of micro-emulsion derived lead magnesium niobate, J. Am. Ceram. Soc. 82 (1999) 529.

[19] M.C. Lopez Blanco, B. Rand, F.L. Riley, The properties of aqueous phase suspensions of barium titanate, J. Eur. Ceram. Soc. 17 (1997) 281-287. 